Volume 5, Issue 2, June 2020, pp. 130-147

DOI: $10.23917 /$ jramathedu.v5i2.9920

p-ISSN: 2503-3697, e-ISSN: 2541-2590

\title{
Social media usage among pre-service secondary mathematics teachers in Zambia
}

\author{
Eddie Mumba Mulenga1* , José María Marbán² \\ ${ }^{1}$ School of Doctoral Studies, University of Valladolid, Spain \\ ${ }^{2}$ Department of Experimental, Social and Mathematical Sciences Teaching, University of Valladolid, Spain \\ *Corresponding author: eddiecaliber@gmail.com
}

\begin{abstract}
ARTICLE INFO
Article history:

Received: 16 January 2020

Revised: 1 May 2020

Accepted: 5 May 2020

Published online: 18 May

2020

Published regularly: June

2020

Keywords:

Attitudes, digital learning, mathematics, pre-service teachers, social media

\section{ABSTRACT}

Social media technologies have reshaped our lives today and Zambian teachers do a massive use of smart phones, tablets, and other portable tools. In addition, they are continually searching for forefront innovations. Frequently, the utilization of these gadgets is not in manners foreseen by innovation advocates. This study focuses on exploring the use of social media platforms and the impact of such social networking services in the teaching and learning of mathematics by pre-service teachers. To explore pre-service teachers' use of social media in their teaching and learning experiences, the authors administered an adapted and validated research instrument via a quantitative survey system to a sample of 102 pre-service teachers from the Copperbelt University. Analysis of variance and multiple regression analysis were used to test the interplay of relationships between pre-service teachers' attitudes towards the use of social media based on year of study and gender, social media use and classroom integration, social media use, and mathematics pedagogy. Further, a statistical test was run to show whether positive correlations existed or not. Results disclosed that respondents showed an average use of social media tools in mathematics and provide a prediction model for pre-service teachers' future integration of social media in the teaching and learning of mathematics.
\end{abstract}

(C) 2020 Universitas Muhammadiyah Surakarta

\section{Introduction}

Mostafa $(\underline{2015})$ defined social media in the Web 2.0 context as "... the usage of Webbased tools like YouTube, Facebook, Twitter, WhatsApp, Gmail, Yahoo mail, Instagram, Google, etc that connect people and allow them to share information, videos, pictures, and so on..." Using this definition as a starting point it can be said that the role of emerging social media may offer new opportunities to reinforce the teaching and learning experiences in Zambia. Zepke and Leach (2010) posited that motivation and student dispositions would influence their ability to engage in interactive learning. It is not surprising that a user can actively participate in activities on social media platforms by sharing contents and opinions, debating, and creating different kinds of groups for different needs (Alabdulkareem, 2015). 
There has been a steady increase in recent studies primarily focusing on the usage of social media in learning. Thus, several scholars have carried out studies on social media use reporting significant knowledge needed in the context of teaching mathematics (Sheikh, Sheikh \& Soomro, 2019; Lau, 2017; Delegge \& Wangler, 2017; Chun \& Lee, 2017; Moorthy et al., 2018; Chukwuere \& Bonga, 2018; Park, Song \& Hong, 2018; Mahmud, Ramachandiran \& Ismail, 2018).

Not astonishingly, considering its popularity, many recent studies have been conducted on Facebook use (García-Domingo, Aranda \& Fuentes, 2017; Cuesta, Eklund, Rydin \& Witt, 2019; Madge, Meek, Wellens \& Hooley, 2009; Kabilan, 2016; Santos \& Čuta, 2015; Gwena, Chinyamurindi \& Marange, 2018) and the use of WhatsApp (García-Domingo, Fuentes \& Aranda, 2018).

In spite of the evidence that much research on social media usage have been done in various fields like Psychology, medical health, medical professions, public sector and cardiovascular imaging (Ayanso \& Moyers, 2015; Liyanapathirana, 2019; Parwani, Lee, Khalique \& Bucciarelli-Ducci, 2019; Demirtepe-Saygll, 2019), there is a dearth of research conducted on social media usage by university students focusing on mathematics. It is against this background that the current study wants to bridge the gap of knowledge in the field of mathematics in the particular context of Zambia. General findings from the studies previously mentioned indicated that social media were used mostly for communication, corroborative discussions, sensitizing patients and research results dissemination. Likewise, the government and other public service agencies use social media platforms as the key channel for communication and service provision.

Tess (2013) carried out a literature review of research on the role of social media in higher education classrooms. He posits that the majority of studies examining learning outcomes and student engagement in connection with social media usage in university settings report positive findings. Lim, Agostinho, Harper, and Chicharo (2014) disclosed that $90 \%$ of the students used social media for academic purposes like answering of assignments, collaboration, sourcing and sharing of information, discussions, and sharing class schedules and activities.

Piotrowski (2015) found that over $50 \%$ of business students and business faculty members had a positive attitude for integrating social media into teaching. Dogoriti, Pange, and Anderson (2014)found that social media platforms were beneficial for teaching and learning. It was further reported that the majority of the pre-service teachers displayed positive values and attitudes towards social media use during learning. This helps them broaden their social networks within a learning atmosphere. A few viewed the social media platforms as tools that can enhance the learning process among students.

Exploring the best way to use social media technologies in classrooms remains a precedence research subject and "continuing challenge" in Mathematics Education (English \& Kirshner, 2015). The increase of digital devices has had immense impacts on mathematics curricula and there has been a continuous rise in instructors flipping their instructions (De Araujo et al., 2017). For example, when teaching mathematics, although instructors may use already-made-videos, many choose to make their own videos and 
some instructors have discovered that their students prefer instructor-made-videos (Palmer, 2015).

There is an increasing interest in African advanced education in the utilization of PCs, tablets, and cell phones to ease the learning process (Bass, 2007; Hennessy, Harrison, London \& Wamakote, 2010). All these gadgets come with various in-built applications to enable one to engage in any online social network. Computers and their in-built social media applications are increasingly breaking the norm of teaching. Research (e.g., Ayub, Mokhtar, Lua \& Tarmizi, 2010) has shown that social media use in instructions, by and large, improves the nature of teaching. Likewise, numerous African nations are urging educators to use computerized assets in their instructions and planning strategies for viable practice (Hennessy et al., 2010). The utilization of computerized gadgets, for example, PCs, telephones, and tablets in the African instruction framework are expanding with the view of improving the nature of teacher training (e.g., Hennessy et al., 2010; Ottevanger, van den Akker \& de Feiter, 2007). It is on these premises that this current study is framed.

In the present investigation, Activity Theory (AT) is the lens used to guide the data analysis and data interpretation to investigate the components that influence undergraduates' interests in online interactions through Web 2.0 innovations. As indicated by Hasan and Kazlauskas ( $\underline{2014}$ ), AT is grounded in the crafted art by the Russian analyst Vygotsky and his students, specifically, Leontiev, during the 1920s. Engeström (2014) reconceptualized the three-level Vygotsky's triangle of human activity mediated by artifacts/tools and Leontiev's three-level triangle of socially mediated activity and developed an extension of the activity theory model comprising of six related principles (Figure 1) namely subject, object, community related to Leontiev and division of labour, rules and tools.

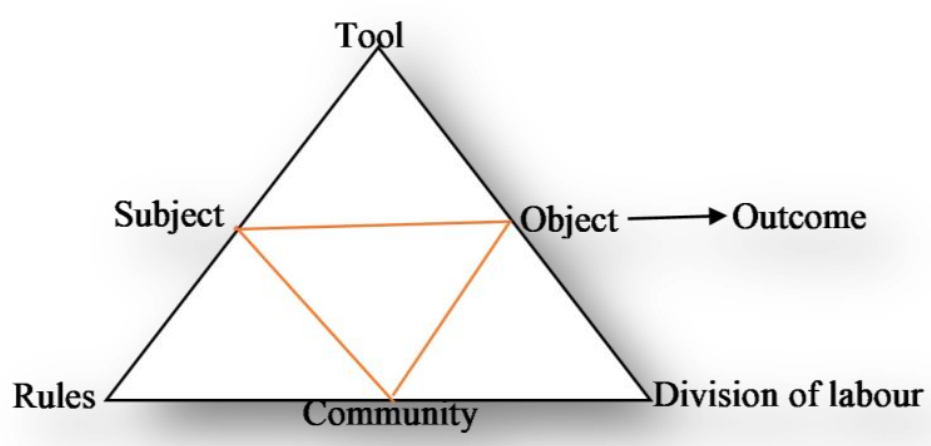

Figure 1. Leontiev's theory of human activity as depicted by Engeström (1987)

Engeström (2014) elaborated on Leontiev's notion of human activity and somehow depicted as embedded triangles (Figure 1) — the Subject-Object-Community triangle of prehuman activity expanded with socially constituted forms of mediation: instruments, rules, and division of labor. Therefore, Engeström (2014) adds the component of community sharing of the same object. In this model, he further included guidelines that intercede the learning network and the subject and divide work between the network and the object. 
Finally, Engeström (2014) gives all the definitions of the six related principles of the theory.

The first principle is the involvement of the object. The framework has social and cultural properties, for example, community-oriented or agreeable learning in an online course. In today's online classroom, every mathematics pre-service teacher can have a front-row seat thereby increasing the chances for participation and engagement. Preston et al. $(\underline{2010})$ posited that most learners revealed that they learn similarly in internet learning platforms, for example, WhatsApp groups, Facebook pages, Twitter texts and Google+ online interactions as they do in lecture settings that are held in the classroom halls within the sight of different learners.

Subjects are on-screen characters occupied with exercises. This is viewed as the individual degree of AT; undergraduates are logical subjects occupied with synergistic learning. An investigation by $\mathrm{Lu}$ and Churchill (2014), uncovered that the educator assumes a foremost job in directing undergraduates in online learning. This may imply that mathematics pre-service teachers are expected to take a center stage in online mathematics activities and act as tutors or instructors on social media platforms as they collaborate with fellow mathematics colleagues in the creation of knowledge and sharing during the mathematics learning process. AT invigorates experts to restore knowledge (Tillema \& Orland-Barak, 2006) through social connections.

Networking is viewed as a social setting of the framework and a network level of AT; all participants are engaged in the activity system (e.g., a gathering of undergraduates occupied with learning dependent on the social connection for building and sharing of information is a case of a learning network). Hewitt (2004) used AT to assess learning networks in web-based learning situations and investigate the components that impact pre-service teachers' cooperation in online networks. Such pre-service teachers are able to create online community platforms for learning mathematics such as mathematics WhatsApp groups, YouTube channels, Facebook pages, Quora spaces, Twitter, and so on for collaborations, discussions, feedback, and sharing of Mathematical content. Through such communities, teachers can create school portals for administrative purposes and the quickest way of disseminating information to students and faculty members.

Instruments or tools are viewed as a mechanical degree of AT. In the framework, correspondence between networks is interceded by devices that transmit social information. This incorporates the artifacts used by actors (pre-service teachers) in the framework. Instruments impact on-screen structure interactions which are affected by culture. Teachers with technological skills and the knowledge of the use of social media platforms like YouTube, Skype, Life-size, Zoom, and Viber. would be able to embrace social media tools especially if they are user friendly and useful to exploit in an online classroom situation as these are appropriate components that may influence undergraduates' frames of mind toward the selection of web-based learning networks to develop and share mathematics. Teachers with this knowledge would be able to use different methods and strategies of teaching and prepare their mathematics lesson plans that center round concepts and skills found in topics that are enhanced using social software tools. 
Division-of-labour is viewed as a various leveled structure of movement or the division of exercises among on-screen characters in the framework. Such mathematics teachers can share or divide tasks to be performed among themselves. Engestrom added this rule in order to enable teachers to mediate the learning community and the subject and create a division-of-labour between the 'community' and the 'object'. This is important for mathematics teachers to comprehend as the training of tomorrow's teachers to use social media platforms is among many other cardinal issues encountered by teacher education training programs today. Suitable use of social media technologies affects all areas of Mathematics Education-what mathematics is taught; how mathematics is taught; and how mathematics is assessed in secondary schools. Teachers ought to see how to divide their labour to cover the school curriculum with the newly proposed teaching approaches with the inclusion of social software technology in their classroom interactions.

Rules are the standard guidelines controlling pre-service teachers' participation in the system of activities. For example, rules of conversation between pre-service teachers in online oriented learning. Teachers must create and give rules of engagement for any online platform created for mathematics such as WhatsApp groups or Facebook pages among many others. Sticking to the rules would enable teachers to post relevant content related to mathematics only. For most social media platforms, group administrators are there to moderate and guide the group members' discussions, keep the rules and remind members about the purpose of the group, in this context, Mathematics Educational purposes.

Activity Theory is the conceptual framework which enables scholars to discover factors that impact undergraduates' investment in online connections. Analysts often use AT to investigate human-PC social collaborations (Nardi, 1996). Along these lines, right now AT was a reasonable structure through which to configure, comprehend, and improve learning through internet learning stages.

The present research about teachers' usage of social media in mathematics education was motivated from a broader introspection by Alabdulkareem's study (Alabdulkareem, 2015) which exclusively analyzed the use of social media from the context of learning science which was one of the most in-depth studies about teachers' and students' stance on social media use in learning. Arguably, pre-service teachers need both digital resources and the use of flipping instructional methods (De Araujo, Otten, \& Birisci, 2017) such as assigning instructional videos or multimedia for students to watch as take-home tasks and completing problems or exercise sets in class to effectively teach mathematics in mathematics classrooms.

In order to understand the contributions of this research to the latent gap of the results from previous studies, we must start saying that although globally many studies have been conducted on the integration and benefits of social media in and out of the classrooms (see e.g. Tess, 2013), such global studies cannot be straightforward applied to the Zambian context and, in particular, to mathematics education in Zambia. This study endeavoured to lessen such knowledge gap. The idea of incorporating social media to the teaching, studying, and learning of mathematics is very important as well as new to be studied because the formal educational system in Zambia supporting studying does not officially include any social media technological properties. This is to some extent due to the low levels of technology usage in Zambian higher learning institutions that can be attributed to limited technological resources (Sintema, 2020). 
The present study is conducted with undergraduate students of Mathematics Education to explore students' usage of social media in the context of a "standard" math subject and other mobile applications compared to $100 \%$ in-class mathematics learning. This paper aims at investigating pre-service teachers' social media usage and its impact on the learning and teaching of mathematics as a scaffolding tool. The paper argues that preservice teachers can learn from informal learning situations using what's available in their hands to create a meaningful learning experience in formal education. This assertion agrees strongly with Perienen (2020) whose study disclosed that students learn mathematics better with effective and convenient technological tools. Not surprisingly, online instructors, tutors, and students are using mobile technologies in universities around the world (Snoussi \& Kaleel Kaleel, 2019; Valunaite Oleskeviciene \& Šliogerienè, 2020; Ifijeh et al., 2019). In the present study, the key questions to answer are: how do preservice teachers use mobile technologies such as WhatsApp, Facebook, Twitter, Instagram, Wechat, e-mail, and another web 2.0 tool in online communities for learning mathematics? Do Mathematics Education pre-service teachers believe that the official usage of social media can enhance their learning and teaching experience in mathematics?

Therefore, this study will focus on providing a deep insight into the way social media technologies are influencing the teaching and learning of mathematics at the Copperbelt University (CBU) as well as to identify which paths are open (or closed) to take into account in the future to improve both processes. Similar to other previous studies (see e.g. Falcó et al., 2020; Giannakoulopoulos et al., 2020; Hennessy et al., 2020), which have looked at classroom innovation with social media in higher education. Thus, the first target of this study is to explore the role social media is playing (and might play) in Mathematics Education via social networking among pre-service teachers. A second target of the research is to explore aspects of university pre-service teachers' related online activities that might motivate them to participate in learning. Lastly, the authors wish to open a discussion on the question of whether and how the use of social media tools may have an impression on the set of 21st-century skills by both learners and teachers.

\section{Research Methods}

The present study is a piece of a bigger existing project that utilized a mixed-methods sequential explanatory design. The essence of choosing the mixed-methods research approach in this study is merely to seek for participants' inputs; this step will provide an all-round view and give an in-depth description of a situation under study. Furthermore, the rationale behind the mixed-methods approach is to gain a better understanding of the statement of the problem and finally to increase the credibility of the authors' findings. However, for the purpose of our current study, a quantitative-method approach was preferred because the quantitative data that was collected and its analysis provided a general understanding of the problem statement (Creswell 2014). In addition, this study adopted a quantitative survey research design (see Figure 2) because of the type of research questions the study seeks to answer and the statistical analysis techniques performed. For instance, this quantitative study sought to address two questions. The first question was concerned with pre-service teachers' usage of social media platforms for 
mathematics e-learning whereas the second was about the pre-service teachers' official usage of social media technologies in mathematics education. Apart from this, the quantitative method and its subsequent analysis techniques aimed at testing the inter-play of relationships between pre-service teachers' usage of social media based on year of study and gender, social media usage skills and classroom integration, social media usage and mathematics pedagogy, profiles of social media usage in mathematics and future classroom integration. Therefore, the results reported in this study are just a part of the quantitative analysis that was run which matches a post hoc quasi-experimental design using a survey technique. A comprehensive set of results for both quantitative and qualitative analysis will be published later when the project is finalized. Therefore, a visual representation is shown below which summarizes all the steps that will be taken in this study during this quantitative phase.

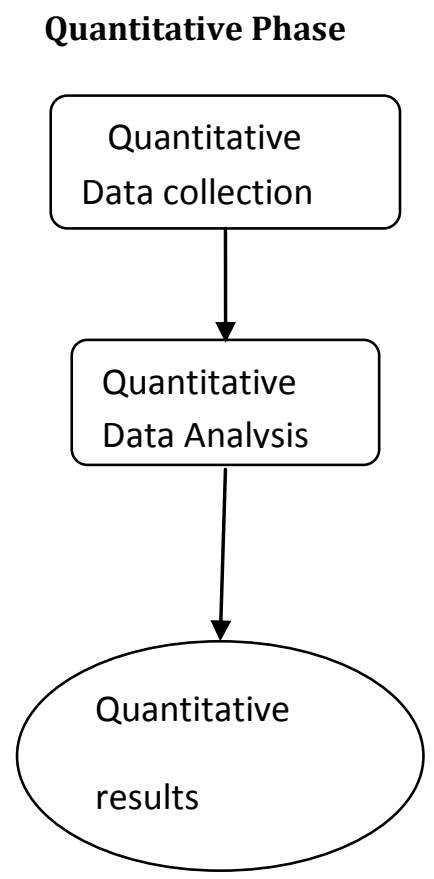

\section{Procedure}

- Quantitative survey

- Face to face-Questionnaire administration $(\mathrm{n}=102)$

- $\quad$ SPSS Data Screening- Univariate /Multivariate

- Descriptive statistics

- Frequencies

- The ANOVA

- Multiple regression Analysis (MA)

- Presentation of quantitative results

- Interpretation of quantitative results

\section{Product}

- Numeric data

- Descriptive statistics, missing data, linearity, homoscedassticity, normality, multivariate outliers,

- Relationships

- Correlations

- QSR NVivo 8.0 software

- Discussion

- Conclusion

- Implications

- Future research

Figure 2. Visual model of a quantitative research design (adapted from Creswell, 2014)

\section{Participants}

A convenience sampling technique was used to determine the genuine sample for this study. Thus, 102 pre-service secondary school mathematics teachers participated in the study. Respondents are Zambian pre-service teachers studying at the Copperbelt University (CBU) in their $3^{\text {rd }}$ and $4^{\text {th }}$ year of their training programs. All the respondents were in the Faculty of Mathematics and Natural Sciences during the 2019/2020 academic year. At the appropriate time, all the respondents need to finish four years to get a fouryear certification in Mathematics Education at CBU.

\section{Instrument}

To measure knowledge of the pre-service secondary school teachers' usage of social media in their teaching and learning experiences, the authors adapted the validated science 
research questionnaire by Moll \& Nielsen (2017). To narrate briefly, this scale underwent two cycles of validation processes with two different groups during its development phases. That is, a total of 220 and 161 pre-service teachers who were at an Australian university during the academic year 2012 and 2013 respectively participated in studies which established the validity and reliability of the scale. Thus, within each science learning context, the authors of the current paper adapted the validated scale to fit within each mathematics learning context and then underwent a complete process of validation before administering it to the current study's participants. For the purpose of our current study, the first stage in the reliability and validation process of the scale involved face validation. That is, a trial run of the scale was carried out with 10 randomly selected participants from the study population. Based on their responses, minor modifications concerning the wording of various statements were produced. The scale was then given to four experts in mathematics education from different universities for face validation examinations and clarity of the items. Their positive comments and suggestions were recorded. The scale was then refined. This was done to make sure that all the questions asked in the questionnaire were clearly understood before conducting the survey at the research site. Additionally, an exploratory factor analysis was conducted separately for each section of the scale to examine the construct validity of the items measured on this scale. Internal reliability for each section of the scale was also computed before carrying out any other statistical test (see Table 1 below). The results of this study indicated that the responses to the questionnaire had a reliability coefficient that was incredibly high. Items on the scale covered five sections on social media usage namely demographics and everyday social media usage; frequency use of social media in mathematics learning (e.g in a third-year or fourth-year mathematics course); Apps to support mathematics learning, online mathematics learning behaviours and resources accessed. The first three sections are the focus of the project from which this study originates. Participants were solicited to selfreport a level of expertise with the recorded internet-based social media tools. Participants were additionally requested some information about explicit internet-based life practices for learning by choosing how frequently (never, sometimes, or regularly) specific practices were used. The questionnaire included 7 pages with tick-box reaction blank spaces and the last part asked 10 open-ended questions. The survey was conducted during a regular class day meeting of a mathematics class that incorporated the whole cohort of forthcoming secondary mathematics teachers. The delivery mode was face-to-face in lecture rooms and in the presence of the researcher.

\section{Data Analysis}

To analyze data, SPSS 24.0 software was used. Descriptive statistics were used to explore the data. Analysis of variances (ANOVA) was performed to check the mean differences in Zambian mathematics pre-service teachers' attitudes towards the use of social media based on gender and year of study. Multiple linear regression analysis (MA) was used to predict the regression model on social media usage in the teaching of mathematics. Again MA was run to examine the relationship between pre-service teachers' use of social media to support their mathematics learning and the various types of social media platforms used to participate in online mathematics discourses and mathematics 
classrooms. Thus, for each social media application, participants were asked to rate how they have used social media platforms in their mathematics learning at the University by responding to 12 listed items on a four-point Likert Scale (1=Non-user: Never heard of it or never used it, 2=Infrequent User: use it sometimes, 3=Frequent User: use it regularly and $4=$ Contributor: frequently use this application to both read content and to contribute content) as shown on Table 1 below.

\section{Results and Discussion}

As a first step in the analysis process, we wanted to test for the validity and reliability of the research instrument used. This was a necessary condition for us since we wanted to obtain high-quality research results. Thus, Cronbach's alpha tests were performed in SPSS for each of the variables (items) of the questionnaire to test for internal consistency. The majority of the items on the questionnaire performed well on this test as shown in Table 1 below.

Table 1

Testing for internal consistency-Cronbach's alpha values

\begin{tabular}{lcc}
\hline Section of the questionnaire & Number of items & Cronbach's alpha value \\
\hline Social media use in everyday life & 12 & 0.713 \\
Apps to support maths learning in Mxxx & 13 & 0.747 \\
Frequency use of SM in maths learning & 17 & 0.733 \\
online mathematics learning behaviours & 9 & 0.710 \\
Resources accessed & 11 & 0.650 \\
\hline
\end{tabular}

From Table 1, the alpha coefficient for the 13 items is 0.747 , followed by 17 items with ( $\alpha=0.733), 12$ items with $\alpha=0.713$ and 9 items with $\alpha=0.710$, suggesting that the items have relatively high internal consistency (since a reliability coefficient of 0.70 or higher is considered acceptable in most social science research situations). This shows that nearly all the 62 items are closely related to each other as a group on the scale and fall within the levels of acceptance. A low alpha value $(\alpha=0.650)$ recorded may be due to the low average of the inter-item correlation or the low number of items.

Results from Table 2 show respondents' choices of social media platforms used to support their mathematics discourses. Based on the Activity Theory of this study, results indicated that Social networking (e.g., Facebook) had the highest preference (78.4\%), followed by Communication (e.g., MSN chat, email, text messaging) (77.5\%), Wikis (e.g., Wikipedia, Wikispaces) (77.5\%), Video sharing (e.g., YouTube) (77.5\%), Document managing and editing tools (e.g., Google documents, Dropbox) (60.8\%), Discussion Forums (e.g., Yahoo answers, ask.com) (48\%) and Social news (e.g., Reddit) (32.4\%). These results agree with Tsai et al., (2010), who also used Activity Theory to examine the social interaction of students' online learning and the digital tools they employed. The current findings are replicated in a study by Sharma \& Shukla (2016) who reported that among Indian college students, social media was used as a cheaper online medium for chatting with friends, keeping in touch with family, and sharing pictures, documents and videos. Consistent with Anna (2019), the current results seem to suggest that mathematics preservice teachers at CBU were primarily using social media platforms like YouTube to watch, download or upload mathematics videos related to their classroom lectures. It is 
also argued in the current study that the use of social media in mathematics learning processes would reduce the learner-teacher dependency syndrome as pre-service teachers can learn on their own through online interactions. However, pre-service teachers had deep concerns about possible unfamiliarity with other social media platforms like Life-size.

Table 2

Statistics of students' responses to social media usage in mathematics learning

\begin{tabular}{lllll}
\hline Social Media Platforms & Non-user & Infrequent User & Frequent User & Contributor \\
\hline $\begin{array}{l}\text { Social networking (e.g., Facebook) } \\
\text { Communication (e.g., MSN chat, email, }\end{array}$ & $21.6 \%$ & $33.3 \%$ & $37.3 \%$ & $7.8 \%$ \\
text messaging) & $22.5 \%$ & $28.4 \%$ & $42.2 \%$ & $6.9 \%$ \\
Blogs (e.g., Tumblr) & $85.3 \%$ & $12.7 \%$ & $2.0 \%$ & $0.0 \%$ \\
Micro-blogging (e.g., Twitter) & $82.4 \%$ & $14.7 \%$ & $2.9 \%$ & $0.0 \%$ \\
Document managing/editing tools & $39.2 \%$ & $25.5 \%$ & $34.3 \%$ & $1.0 \%$ \\
(e.g., Google documents, Dropbox) & & & & $0.0 \%$ \\
Social bookmarking (e.g., Delicious) & $89.2 \%$ & $6.9 \%$ & $3.9 \%$ & $0.0 \%$ \\
Social news (e.g., Reddit) & $67.6 \%$ & $19.6 \%$ & $12.7 \%$ & $2.0 \%$ \\
Wikis (e.g., Wikipedia, Wikispaces) & $22.5 \%$ & $30.4 \%$ & $45.1 \%$ & $2.0 \%$ \\
Video sharing (e.g., YouTube) & $22.5 \%$ & $19.6 \%$ & $55.9 \%$ & $1.0 \%$ \\
Live casting (e.g., Skype, Life size) & $84.3 \%$ & $10.8 \%$ & $3.9 \%$ & $1.0 \%$ \\
Photography sharing (e.g., Flickr) & $77.5 \%$ & $12.7 \%$ & $8.8 \%$ & $2.0 \%$ \\
$\begin{array}{l}\text { Discussion Forums (e.g., Yahoo answers, } \\
\text { ask.com) }\end{array}$ & $52.0 \%$ & $27.5 \%$ & $18.6 \%$ & $0.0 \%$ \\
UoW Learning management system & $94.1 \%$ & $3.9 \%$ & $2.0 \%$ & \\
(SMP) & & & & \\
\hline
\end{tabular}

Results in Table 3 revealed that at a 95\% confidence level, there were no significant differences based on year of study in the mean scores of pre-service teachers for males and females. In verifying the hypothesis, the overall results revealed that the use of social media in mathematics pedagogy did not depend on either gender or year of study. In contrast, the previous studies about gender, although in the context of Facebook usage only as a social media platform, other studies have found quite the opposite. For instance, García-Domingo et al. (2017), discovered a different pattern of utilizing Facebook between males and females. In their study, females seemed to be more active than males. On the other hand, the findings in this study did not specifically give any reference. On average, both males and females irrespective of their year of study moderately used social media platforms in mathematics activities. Based on the activity theory of this study, we see that both male and female pre-service teachers are motivated and positively oriented to participate in online communities to share knowledge related to mathematics courses. This is consistent with Murphy \& Littlejohn (ㅁ19), who similarly used activity theory to analyze the social networking of participants.

Table 3

Pre-service teachers' usage of social media based on gender and year of study

\begin{tabular}{cccccc}
\hline & & & \multicolumn{2}{c}{$95 \%$ Confidence interval } \\
\cline { 5 - 6 } Gender & Year & Mean & Std. Error & Lower Bound & Upper Bound \\
\hline \multirow{2}{*}{ Male } & 3rd Year & 3.122 & .382 & 2.362 & 3.881 \\
& 4th Year & 3.345 & .453 & 2.445 & 4.244 \\
Female & 3rd Year & 3.167 & .717 & .741 & 3.592 \\
& 4th Year & 3.222 & .492 & 2.245 & 4.199 \\
\hline
\end{tabular}


Table 4 shows respondents' rate of agreement with 17 items on a 3-point Likert scale ( 1 = never, 2 = sometimes and $3=$ regularly) on how frequently they use social media to support their mathematics learning in mathematics courses. The aggregate score represents the sum of the agreement for pre-service teachers who either 'sometimes' or 'regularly' use social media to support their mathematics learning.

Table 4

How frequently do you use social media to support your mathematics learning?

\begin{tabular}{clllllllllllllllll}
\hline Item & $3 \mathrm{a}$ & $3 \mathrm{~b}$ & $3 \mathrm{c}$ & $3 \mathrm{~d}$ & $3 \mathrm{e}$ & $3 \mathrm{f}$ & $3 \mathrm{~g}$ & $3 \mathrm{~h}$ & $3 \mathrm{i}$ & $3 \mathrm{j}$ & $3 \mathrm{k}$ & $3 \mathrm{l}$ & $3 \mathrm{~m}$ & $3 \mathrm{n}$ & $3 \mathrm{o}$ & $3 \mathrm{p}$ & $3 \mathrm{q}$ \\
\hline 1 & 20.6 & 38.2 & 5.9 & 31.4 & 91.2 & 33.3 & 55.9 & 45.1 & 2.9 & 11.8 & 49.0 & 35.3 & 74.5 & 73.5 & 72.5 & 19.6 & 40.2 \\
2 & 56.9 & 48.0 & 23.5 & 46.1 & 6.9 & 40.2 & 33.3 & 35.3 & 18.6 & 34.3 & 41.2 & 52.9 & 18.6 & 19.6 & 22.5 & 33.3 & 39.2 \\
3 & 22.5 & 13.7 & 70.6 & 22.5 & 2.0 & 26.5 & 10.8 & 19.6 & 78.4 & 53.9 & 9.80 & 11.8 & 6.9 & 6.9 & 4.9 & 47.1 & 20.6 \\
\hline Aggregate: & 79.4 & 61.7 & 94.1 & 68.6 & 8.9 & 66.7 & 44.1 & 54.9 & 97.0 & 88.2 & 51.0 & 64.7 & 25.5 & 26.5 & 27.4 & 80.4 & 59.8 \\
\hline
\end{tabular}

3a-Use Facebook chat (or MSN or texting) to contact a friend to get help with a class assignment, 3b-Use e-mails more effectively incommunicatingwith my mathematics lecturersthan in my class, 3c-Use WhatsApp to get help with mathematics assignments/home works/research works etc, 3d- Usee-learning mathematics materials available via social media to learn maths, 3e-Use Skype (or some kind of live casting service) to connect with a friend or a group to work on a class assignment, $3 f$-Ask a mathematics question on an online forum such as Ask.com, 3g-Collaborate with a classmate on an online document using Google docs (or something similar), 3hCreate or join a Facebook group with classmates to share homework, links, and to discuss class content, 3iSearch YouTube for a video to learn about a mathematics concept, 3j-Access Wikipedia to read about a mathematics concept, 3k-Answer or comment on a mathematics related topic on a forum such as Ask.com, 3lRead a mathematics related blog or news items, 3m-Follow mathematicians or maths related feeds on Twitter $3 n$-Save and share maths related bookmarks on Delicious (or some other social bookmarking service), 3o-Post mathematics related content on a blog, $3 p$-Store apps on my Smartphone that are useful for learning mathematics, $3 q$ - share and/or post videos related to my mathematics learning.

Once again, based on the theoretical framework of this study, it was very easy for us to analyze and understand the results reported in Table 4. Activity Theory enabled us to describe and analyze the structure, development, and context of learning activities mediated by mobile technologies, and so on. Using AT as our lens, results from Table 4 showed that the most popular social media platforms used in mathematics activities were YouTube (97\%). That is, majority of the participants (on item 3i) found themselves either sometimes (18.6\%) or regularly (78.4\%) searching YouTube for a video to learn about a mathematics concept, representing a total of $97 \%$, followed by $94.1 \%$ of the respondents found themselves either sometimes $(23.5 \%)$ or regularly $(70.6 \%)$ using WhatsApp to get help with mathematics assignments/home works/ research works, etc (item 3c), $88.2 \%$ would either sometimes or regularly access Wikipedia to read about a mathematics concept (item 3j) and by the foregoing, we see that 79.4\% use Facebook (item 3a), 68.6\% use e-learning platforms (item 3d), 66.7\% use Ask.com (item 3f) and 61.7\% use Gmail (item $3 b$ ). On the other hand, pre-service teachers had deep concerns of possible unfamiliarity with other social media technologies like Tumblr, Twitter, delicious, Zoom, Life-size, Flickr, and Reddit and recorded low scores. For instance, $74.5 \%$ of the participants never follow mathematicians or mathematics-related feeds on Twitter (item $3 \mathrm{~m}$ ), and $73.5 \%$ never save and share mathematics-related bookmarks on Delicious (item $3 \mathrm{n}$ ). The high use of YouTube is not surprising as the application is user friendly. Anna (2019; p. 7) posited that "...YouTube is one of the most important applications downloaded by pre-service teachers on their Smart phones. Pre-service teachers use YouTube, in addition to being an entertainment medium, as a source of information to search for lecture material, pre-service teachers use YouTube to find tutorial videos related to lecture material..." Pre-service teachers also use WhatsApp, Facebook, Gmail, and other e-learning 
platforms whenever they need to access assignments from lecturers, upload assignments, and obtain information associated with lectures (Anna, 2019). This is quite encouraging as pre-service teachers at CBU do not only use social media for social purposes but the majority of them see it as a tool for teaching and learning mathematics. Consistent with Wickramanayake and Jika (2017) social media tools function through different platforms to provide various services to their members, and the participants' choices of platforms and their use in mathematics teaching and learning are summarized in Table 2 and 4.

Table 5

Analysis of pre-service teachers' social media usage in teaching mathematics

\begin{tabular}{|c|c|c|c|c|c|c|}
\hline \multicolumn{2}{|c|}{ Model } & Sum of Squares & Df & Mean Square & $\mathrm{F}$ & Sig. \\
\hline \multirow[t]{3}{*}{1} & Regression & 6.364 & 1 & 6.364 & 6.015 & $.016^{\mathrm{b}}$ \\
\hline & Residual & 102.626 & 97 & 1.058 & & \\
\hline & Total & 108.990 & 98 & & & \\
\hline \multirow[t]{3}{*}{2} & Regression & 12.486 & 2 & 6.243 & 6.211 & $.003^{\mathrm{c}}$ \\
\hline & Residual & 96.504 & 96 & 1.005 & & \\
\hline & Total & 108.990 & 98 & & & \\
\hline \multirow[t]{3}{*}{3} & Regression & 18.407 & 3 & 6.136 & 6.435 & $.001^{\mathrm{d}}$ \\
\hline & Residual & 90.583 & 95 & .954 & & \\
\hline & Total & 108.990 & 98 & & & \\
\hline \multirow[t]{3}{*}{4} & Regression & 22.680 & 4 & 5.670 & 6.175 & $.000^{\mathrm{e}}$ \\
\hline & Residual & 86.310 & 94 & .918 & & \\
\hline & Total & 108.990 & 98 & & & \\
\hline \multirow[t]{3}{*}{5} & Regression & 27.103 & 5 & 5.421 & 6.156 & $.000^{\mathrm{f}}$ \\
\hline & Residual & 81.886 & 93 & .880 & & \\
\hline & Total & 108.990 & 98 & & & \\
\hline
\end{tabular}

Dependent Variable: Social media usage in teaching mathematics

Predictors: (Constant), Social media tools have a place in my Mathematics teaching subject, Year, share online resources (links, documents) for learning Mathematics with my classmates., Frequency use of social media for personal purposes, Look for a video to teach me about the Mathematics concepts

Results indicate that the variables added statistically significantly to the prediction of pre-service teachers' usage of social media platforms in the teaching of mathematics as $F$ $(1,97)=6.015, p=0.016<0.05$. Table 5 disclosed that positive correlations existed between pre-service teachers' attitudes towards the use of social media and year of study, gender and social media usage skills, classroom integration and mathematics pedagogy, profiles of social media usage in mathematics, and future classroom social media integration. By implication, pre-service teachers have a strong desire to incorporate social media tools in the teaching and learning of mathematics in the future. These results seem to agree powerfully with the findings of Acarli and Sağlam ( $\underline{2015}$ ) whose study participants were also eager to use social media in their professional lives. This is interesting as activity theory examines online interactions beyond personal benefits. At the professional level, we see pre-service teachers working cooperatively and collaboratively as a community (see e.g.Mills, 2017) to learn and integrate social media in mathematics classrooms. 
Table 6

Model Summary of the analysis of social media usage in mathematics

\begin{tabular}{|c|c|c|c|c|c|}
\hline Model & $\mathrm{R}$ & R Squared & $\begin{array}{c}\text { Adjusted R } \\
\text { Squared }\end{array}$ & $\begin{array}{l}\text { Std. Error of } \\
\text { the Estimate }\end{array}$ & Durbin-Watson \\
\hline 1 & $.242^{\mathrm{a}}$ & .058 & .049 & 1.029 & \\
\hline 2 & $.338^{b}$ & .115 & .096 & 1.003 & \\
\hline 3 & $.411^{c}$ & .169 & .143 & .976 & \\
\hline 4 & $.456^{d}$ & .208 & .174 & .958 & \\
\hline 5 & $.499 \mathrm{e}$ & .249 & .208 & .938 & 2.048 \\
\hline \multicolumn{6}{|c|}{$\begin{array}{l}\text { Predictors: (Constant): } \\
\text { a-Social media tools have a place in my mathematics teaching subject, b-Year, c-share, } \\
\text { online resources (links, documents) for learning Mathematics with my classmates d- } \\
\text { Frequency use of social media for personal purposes, e-Look for a video to teach me about } \\
\text { the Mathematics concepts } \\
\text { Dependent Variable: Social media usage in teaching mathematics. }\end{array}$} \\
\hline
\end{tabular}

Results from Table 6 show the variability in the pre-service teachers' usage of social media in the teaching of mathematics as explained by five statistically significant predictors (see Table 5). The adjusted R square adjusts for the number of terms in the model. As it can be seen it increases from model 1 to 5 meaning that the new terms added to improve the model fit more than expected by chance alone. It is, therefore, logical to conclude that social media tools have a place in pre-service teachers' mathematics teaching subjects as they progress from $3^{\text {rd }}$ year to $4^{\text {th }}$ year through their training program of study. At the time students enroll as first years at CBU, most of them are already exposed to social media technologies and have registered accounts which they use for personal and professional lives. When the average R-values of the respondents were analyzed, one could also conclude that at the end of their Bachelor's degree program, the new graduates are very enthusiastic to use social media in their own mathematics classrooms. These results agree strongly with the results reported in the study conducted by Yusuf and Bolaji (2018) in which most of their participants wished to be inclusive of all social media applications for mobile learning and desired that their lecturers could give them tasks which could be solved through the use of social media in a mobile learning platform. In a sense, pre-service teachers in the current study adopted and accepted the use of social media platforms to engage in academic activities.

The general form of the equation to predict "Social media usage in the teaching of mathematics" is given by;

$$
y=0.242 a+338 b+0.411 c+0.456 d+0.499 e
$$

The estimated model coefficients show a positive prediction of pre-service teachers' future integration of social media in the teaching and learning of mathematics. The findings in the current study seem to strongly agree with the findings of Akakandelwa \& Walubita (2018) at the University of Zambia who reported that most of the sampled students used social media to get new information, stay in contact with friends and for school work.

\section{Conclusion}

The results from this study are relevant in addressing each of the three research questions or targets posed and the objectives of this study have also been met, providing vital information that can lessen the knowledge gap. Moreover, the current findings agree 
with the conclusions of other researchers and studies, highlighting their consistency. In particular, the results obtained have revealed that social media platforms have positively impacted mathematics education in the particular context under consideration and that university pre-service teachers need to tap into these new technologies to effectively use them in teaching mathematics. Besides, social media technologies have come with several other benefits which generally include sharing information, corroboration, exploration, and cost-saving. The results also reflect pre-service teachers' positive attitudes towards the integration of social media platforms in their mathematics classrooms both for learning and teaching. In particular, students are using essentially the same social media in and out of the classrooms (Youtube, Whatsapp, and Facebook) so that activities based in such technological environments seem to highly motivate them. This study has shown that gender and year of study are immaterial to the utilization of social media in the context being considered. However, positive correlations existed between pre-service teachers' attitudes towards the use of social media, year of study, and gender. Finally, results further suggest that the official usage of social media in mathematics instructions would reduce the student-teacher dependency syndrome, enhance students' thinking ability, promote easier and faster communication between or among students and teachers, bring about meaningful learning, and eventually a potential tool to meet all learners needs.

Anyway, the current study just scratches the surface of an area where little information exists and thus "motivates" new lines of research. For instance, it may interest someone to examine how university undergraduates and lecturers actually use social media in mathematics pedagogy and its impact on the academic performance of students. Furthermore, some questions could be adjusted to yield more informative responses. For instance, the questions related to how pre-service teachers believe that the official usage of social media can enhance their learning and teaching experience in mathematics. Findings such as this will not only contribute to a deeper understanding of lecturers' and students' usage of social media and its impact on the teaching and learning of mathematics but will also provide useful information for the design of effective digital instructor-learner education programs not only at CBU but worldwide.

\section{Acknowledgment}

The authors wish to acknowledge the input of four experts in Mathematics Education who selflessly contributed to the review and validation processes of the research scale used in this study. Additionally, our sincere thanks go to all the participants of this study for their time and collaboration

\section{Bibliography}

Acarli, D. S., \& Sağlam, Y. (2015). Investigation of Pre-service Teachers' Intentions to Use of Social Media in Teaching Activities within the Framework of Technology Acceptance Model. Procedia - Social and Behavioral Sciences, 176(20), 709-713. https://doi.org/10.1016/j.sbspro.2015.01.530

Akakandelwa, A., \& Walubita, G. (2018). Students' social media use and its perceived impact on their social life: A case study of the University of Zambia. The International Journal of Multi-Disciplinary Research, 5(3), 1-14. Retrieved from http://dspace.unza.zm/handle/123456789/5247

Alabdulkareem, S. A. (2015). Exploring the use and the impacts of social media on teaching and learning science in Saudi. Procedia-Social and Behavioral Sciences, 182, 213-224. https://doi.org/10.1016/j.sbspro.2015.04.758 
Anna, N. (2019). Top 10 Mobile Apps To Support LIS Students' Learning. Library Philosophy and Practice (e-journal): 2607. Retrieved from https://digitalcommons.unl.edu/libphilprac/2607

Ayanso, A., \& Moyers, D. (2015). Social Media Use in the Public Sector. In Digital Solutions for Contemporary Democracy and Government (pp. 63-85). IGI Global. https://doi.org/10.4018/978-1-5225-9860-2.ch037

Ayub, A. F. M., Mokhtar, M. Z., Luan, W. S., \& Tarmizi, R. A. (2010). A comparison of two different technologies tools in tutoring Calculus. Procedia - Social and Behavioral Sciences, 2, 481-486. https://doi.org/10.1016/j.sbspro.2010.03.048

Bass, J. (2007). A developmental model of basic ICT skills for pre-service trainee teachers. In 2007 International Conference on Information and Communication Technologies and Development (pp.1-10). IEEE. https://doi.org/10.1016/B978-155860808-5/50011-3

Chukwuere, J. E., \& Bonga, S. O. Y. (2018). An exploration in the influence of social media on university students' relationships. WMSCI 2018 - 22nd World Multi-Conference on Systemics, Cybernetics and Informatics, Proceedings, 1(July), 113-118.

Chun, J., \& Lee, M. (2017). When does individuals' willingness to speak out increase on Social Media? Perceived Social Support and Perceived Power/Control. Computers in Human Behavior, 74, 120-129. https://doi.org/10.1016/j.chb.2017.04.010

Creswell, J. W. (2014). Research design: Qualitative, quantitative and mixed methods approaches. Thousand Oaks, CA: Sage

Cuesta, M., Eklund, M., Rydin, I., \& Witt, A.-K. (2019). Using Facebook as a co-learning community in higher education. Learning, Media and Technology, 41(1), 55-72. https://doi.org/10.4324/9781315121697-3

De Araujo, Z., Otten, S., \& Birisci, S. (2017). Mathematics teachers ' motivations for, conceptions of, and experiences with flipped instruction. Teaching and Teacher Education, 62, 60-70. https://doi.org/10.1016/j.tate.2016.11.006

Delegge, A., \& Wangler, H. (2017). Is this the end for Facebook? A mathematical analysis. Applied Mathematics and Computation, 305(February 2004), 364-380. https://doi.org/10.1016/j.amc.2017.02.014

Demirtepe-Saygill, D. (2019). Stress, Coping, and Social Media Use. In The Psychology and Dynamics Behind Social Media Interactions (pp. 241-267). IGI Global. https://doi.org/10.4018/978-1-5225-9412-3.ch010

Dogoriti, E., Pange, J. P., \& Anderson, G. (2014). The use of social networking and learning management systems in English language teaching in higher education. Campus-Wide Information Systems, 31(4), 254-263. https://doi.org/10.1108/CWIS-11-2013-0062

Engeström, Y. (2014). Learning by Expanding: An Activity-Theoretical Approach to Developmental Research (2nd. edition) Cambridge: Cambridge University Press. https://doi.org/10.1017/CB09781139814744

English, L.D., \& Kirshner, D. (Eds.) (2015). Handbook of International Research in Mathematics Education. New York, NY: Routeledge.

Falcó, E., Pérez Domínguez, B., Casaña Granell, J., Calatayud, J., \& Ezzatvar, Y. (2020). College Classroom Innovation With Social Media. In INTED 2020 Proceedings (pp. 49204920). https://doi.org/10.21125/inted.2020.1346

García-Domingo, M., Aranda, M., \& Fuentes, V. M. (2017). Facebook Use in University Students: Exposure and Reinforcement Search. Procedia - Social and Behavioral Sciences, 237(August 2018), 249-254. https://doi.org/10.1016/i.sbspro.2017.02.071

García-Domingo, M., Fuentes, V., \& Aranda, M.A. (2018). Undergraduate students' perceptions on the use of WhatsApp: interferences in daily living. In CUICIID 2018Proceedings (pp. 1163-1166). 
Giannakoulopoulos, A., Limniati, L., \& Konstantinou, N. (2020). Social Media Use By Educational Institutions. In INTED 2020 Proceedings (pp. 6587-6593). https://doi.org/10.21125/inted.2020.1752

Gwena, C., Chinyamurindi, W., \& Marange, C. (2018). Motives influencing Facebook usage as a social networking site: An empirical study using international students. Acta Commercii, 18. https://doi.org/10.4102/ac.v18i1.521

Hasan, H., \& Kazlauskas, A. (2014). Activity Theory: who is doing what, why and how. In H. Hasan (Eds.), Being Practical with Theory: A Window into Business Research (pp. 9-14). Wollongong, Australia: THEORI. Retrieved from http://eurekaconnection.files.wordpress.com/2014/02/p-09-14-activity-theorytheori-ebook-2014.pdf

Hennessy, C., Brown, K., Pascoe, M., Keenan, I., Holland, J., Meyer, A., \& Royer, D. (2020). 21st Century Anatomists: Social Media Use in Anatomy Education and Research. 363363. Abstract from 19th meeting of the International Federation of the Associations of Anatomy, London, United Kingdom. https://doi.org/10.1111/joa.13163

Hennessy, S., Harrison, D., London, \& Wamakote, L. (2010). Teacher factors influencing classroom use of ICT in Sub-Saharan Africa. Itupale online journal of African Studies, 2(1), 39-54.Retrieved from https://pdfs.semanticscholar.org/56ec/ 8d2248a546352fed0f520972b57034334a45.pdf

Hewitt, J. (2004). An exploration of community in a knowledge forum classroom: An activity system analysis. Designing for Virtual Communities in the Service of Learning, 210-238. https://doi.org/10.1017/CB09780511805080.012

Ifijeh, G., Ilogho, J., Iwu-james, J., Michael-Onuoha (Ohaegbulam), H., \& Osinulu, I. (2019). Social Media Use in Academic Libraries (pp. 237-257). https://doi.org/10.4018/9781-5225-8097-3.ch014

Kabilan, M. (2016). Using Facebook as an e-portfolio in enhancing pre-service teachers' professional development. Australasian Journal of Educational Technology, 32, 19-31. https://doi.org/10.14742/ajet.2052

Lau, W. (2017). Effects of social media usage and social media multitasking on the academic performance of university students. Computers in Human Behavior, 68, 286-291. https://doi.org/10.1016/j.chb.2016.11.043

Lim, J. S. Y., Agostinho, S., Harper, B., \& Chicharo, J. F. (2014). The engagement of social media technologies by undergraduate informatics students for academic purpose in Malaysia. Journal of Information, 12. https://doi.org/10.1108/JICES-03-2014-0016

Liyanapathirana, V. (2019). Social media use and medical professionals. Sri Lanka Journal of Medicine, 28. https://doi.org/10.4038/sljm.v28i2.139

Lu, J., \& Churchill, D. (2014). Using social networking environments to support collaborative learning in a Chinese university class: Interaction pattern and influencing factors. Australasian Journal of Educational Technology, 30, 472-486. https://doi.org/10.14742/ajet.655

Madge, C., Meek, J., Wellens, J., \& Hooley, T. (2009). Facebook, social integration and informal learning at university: "It is more for socialising and talking to friends about work than for actually doing work." Learning, Media and Technology, 34(2), 141-155. https://doi.org/10.1080/17439880902923606

Mahmud, M. M., Ramachandiran, C. R., \& Ismail, O. (2018). Social Media Dependency: The Implications of Technological Communication Use Among University Students. In S. F. Tang \& S.E. Cheah (Eds.), Redesigning Learning for Greater Social Impact (pp. 71-87). Singapore: Springer. https://doi.org/10.1007/978-981-10-4223-2

Mills, C. (2017). Activity Theory.The International Encyclopedia of Organizational 
Communication, 1-10.https://doi.org/10.1002/9781118955567.wbieoc001

Moll, R., \& Nielsen, W. (2017). Development and validation of a social media and science learning survey. International Journal of Science Education, Part B: Communication and Public Engagement, 7(1), 14-30. https://doi.org/10.1080/21548455.2016.1161255

Moorthy, M., T'ing, L., Wei, K., Mei, P., Yee, C., Wern, K., \& Xin, Y. (2018). Is facebook useful for learning? A study in private universities in Malaysia. Computers \& Education, 130. https://doi.org/10.1016/j.compedu.2018.12.002

Mostafa, R.B. (2015), Engaging Students via Social Media: Is It Worth the Effort?. Journal of Marketing Education, 37(3), p. 144-159. https://doi.org/10.1177/0273475315585825

Murphy, V., \& Littlejohn, A. (2019). Social network analysis and activity theory.In D. Froehlich, M. Rehm, \& B. Rienties (Eds.) (2020): Mixed Methods Social Network Analysis (pp. 113-125). London: Routledge, https://doi.org/10.4324/9780429056826

Nardi, B. A. (1996). Context and Consciousness: Activity Theory in Human-Computer Interaction. Cambridge, Mass., MIT Press. 1996, 400 pp. [Book Review]. Professional $\begin{array}{lllll}\text { Communication, } & \text { IEEE Transactions } & \text { 242-243. }\end{array}$ https://doi.org/10.1109/TPC.1997.649561

Ottevanger, W., van den Akker, J., \& de Feiter, L., (2007). Developing science, mathematics, and ICT education in Sub-Saharan Africa: Patterns and promising practices. The World Bank.

Palmer, K. (2015). Flipping a Calculus Class: One Instructor's Experience. PRIMUS, 25, 886891. https://doi.org/10.1080/10511970.2015.1050618

Park, E., Song, H. D., \& Hong, A. (2018). The use of social networking services for classroom engagement? The effects of Facebook usage and the moderating role of user motivation. Active Learning in Higher Education. https://doi.org/10.1177/1469787418809227

Parwani, P., Lee, J., Khalique, 0., \& Bucciarelli-Ducci, C. (2019). Social Media Use in Cardiovascular Imaging. Current Cardiology Reviews, 15. https://doi.org/10.2174/1573403X15666191107125304

Perienen, A. (2020). Frameworks for ICT Integration in Mathematics Education - A Teacher's Perspective. Eurasia Journal of Mathematics, Science and Technology Education, 16(6), em1845. https://doi.org/10.29333/ejmste/7803

Piotrowski, C. (2015). Pedagogical Applications of Social Media in Business Education: Student and Faculty Perspectives. Journal of Educational Technology Systems, 43(3), 257-265. https://doi.org/10.1177/0047239515570575

Preston, G., Phillips, R., Gosper, M., Mcneill, M., Woo, K., \& Green, D. (2010). Web-based lecture technologies: Highlighting the changing nature of teaching and learning. Australasian Journal of Educational Technology, 26(6), 717-728. https://doi.org/10.14742/ajet.1038

Santos, D., \& Čuta, M. (2015). The usage of social networks by university students (A survey of Facebook use patterns among young people). Anthropologia Integra, 6, 35-43. https://doi.org/10.5817/AI2015-1-35

Sharma, A., \& Shukla, A. K. (2016). Impact of Social Messengers Especially Whatsapp on Youth: A Sociological Study. International Journal of Advance Research and Innovative Ideas in Education, 5, 367-375. https://doi.org/16.0415/IJARIIE-3111

Sheikh, F., Sheikh, S., \& Soomro, A. (2019). Social Media usage among University Students at University of Sindh Jamshoro. Journal of Mass Communication Department, Dept. of 
Mass Communication, Univeesity of Karachi, 15. Retrieved from https://www.researchgate.net/publication/335685541 Social Media usage among University Students at University of Sindh Jamshoro

Sintema, E. J. (2020). Effect of COVID-19 on the Performance of Grade 12 Students: Implications for STEM Education. Eurasia Journal of Mathematics, Science and Technology Education, 16(7), em1851. https://doi.org/10.29333/ejmste/7893

Snoussi, T., \& Kaleel Kaleel, A. (2019). Social Media Use in Higher Education: A Case Study. Conference Record - International Conference on Communications, 4, 27-35.

Tess, P. (2013). The role of social media in higher education classes (real and virtual) - A literature review. Computers in Human Behavior, 29, A60-A68. https://doi.org/10.1016/i.chb.2012.12.032

Tillema, H., \& Orland-Barak, L. (2006). Constructing knowledge in professional conversations: The role of beliefs on knowledge and knowing. Learning and Instruction, 16, 592-608. https://doi.org/10.1016/j.learninstruc.2006.10.006

Tsai, I.-C., Galyen, K., Xie, X., \& Laffey, J. (2010). Using activity theory to examine social interaction of online learning.In J. Herrington \& C. Montgomerie (Eds.), Proceedings of ED-MEDIA 2010--World Conference on Educational Multimedia, Hypermedia \& Telecommunications (pp. 1202-1211). Toronto, Canada: Association for the Advancement of Computing in Education (AACE). Retrieved May 10, 2020 from https://www.learntechlib.org/primary/p/34785

Valunaite Oleskeviciene, G., \& Šliogerienè, J. (2020). Social Media Use in University Studies. https://doi.org/10.1007/978-3-030-37727-4

Wickramanayake, L., \& Jika, S. (2017). Social media use by undergraduate students of education in Nigeria: A survey. The Electronic Library, 36(1), 21-37. https://doi.org/10.1108/EL-01-2017-0023

Yusuf, H. T., \& Bolaji, H. O. (2018). Predictive Modeling for Social Media Adoption on Mobile Learning for Instructional Delivery in Tertiary Institutions in Kwara State. Journal of Science, Technology, Mathematics and Education 14(3), 105-114. Retrieved from https://www.researchgate.net/publication/333560429

Zepke, N., \& Leach, L. (2010). Improving student engagement: Ten proposals for action. Active learning in higher education, 11(3), 167-177. https://doi.org/10.1177/1469787410379680 